\title{
Feasibility of Extracts of Common Philippine Succulents as Ultrasound Acoustic Gel Alternatives
}

Mark M. Alipio, RRT, MPA, ${ }^{1}$ Ma. Victoria Q. Patrimonio, MD, ${ }^{1}$ Ahmeda B. Ali, RRT, LPT, ${ }^{1}$ Franz Roi T. Talaroc, RRT, ${ }^{1}$ Christian Lou C. Ablin, RRT, ${ }^{1}$ Shahani M. Naim, RRT, ${ }^{1,2}$ Betsy Rose E. Borja, RRT ${ }^{1,3}$ and Grace Meroflor A. Lantajo, DPA ${ }^{4}$

\author{
${ }^{1}$ Iligan Medical Center College, Lanao del Norte \\ ${ }^{2}$ Provincial Health Office - Capitol Complex, Marawi City \\ ${ }^{3}$ Allied Care Experts Medical Center-Bohol \\ ${ }^{4}$ University of Southeastern Philippines, Mintal, Davao City
}

\begin{abstract}
Background. Ultrasound remains to be an ideal imaging tool for the diagnosis of various conditions in the body. However, the cost and unavailability of the commercial acoustic gel continue to hamper the tool's diagnostic value in low-resource communities.

Objectives. The study aims to investigate the feasibility of extracts of common Philippine succulents as ultrasound acoustic gel, based on image quality parameters, organoleptic characteristics, spreadability, $\mathrm{pH}$, and viscosity.

Methods. Aloe Vera, common houseleek, burro's tail, snake plant, echeveria, crown of thorns, panda plant, and jade plant were extracted and filtered before subjecting them for a physical evaluation. The evaluation analyzed the organoleptic characteristics, spreadability, $\mathrm{pH}$, and viscosity of the formulated gels. The commercial acoustic gel was used as the reference gel. Three experienced ultrasonographers blindly evaluated a total of 243 images obtained using the formulated gels based on four image quality parameters.
\end{abstract}

Results. The formulated gels had optimal appearance, texture, homogeneity, and $\mathrm{pH}$ value. However, all of the extracts had a lower viscosity than the commercial reference gel. The extract obtained from the burro's tail exhibited the highest viscosity among the tested extracts. There was no significant difference in the image quality parameters among the commercial and formulated gels.

Conclusion. The extracts obtained from the succulents are feasible as an acoustic gel for ultrasound imaging based on the physical and image quality analyses. The tested plants are readily available and easy to produce compared to commercial acoustic gel.

Key Words: Ultrasound gel, Natural products, Philippine succulents

\section{INTRODUCTION}

Corresponding author: Mark M. Alipio, RRT, MPA Iligan Medical Center College

Pala-o, Iligan City, Lanao del Norte 9200, Philippines

Email: markmalipio@gmail.com
Ultrasound is an imaging modality used to analyze the anatomy and physiology of various soft-tissue organs in the body. It is especially valuable in the diagnosis of pathological conditions in the abdomen and thyroid gland, as well as in the imaging of fetus and pregnant women's uterus and ovaries. To produce images, the ultrasound machine's probe sends off high-frequency sound waves towards the organ of interest. The probe also acts as the data collector of the images obtained. However, an air gap exists between the probe and skin surface, which results in reduced image resolution and inaccurate interpretation of anatomy, physiology, and diagnosis. ${ }^{1,2}$ To solve this problem, an acoustic gel is placed on the probe. 
The acoustic gel is a colorless viscous fluid that contains mucilaginous agents to improve the transmission of sound waves from the ultrasound probe to the organ of the body. It removes the air gap between the probe and skin surface, thus augmenting the intensity of sound waves delivered to the body. The commercially-available acoustic gel contains carbomer, ethylenediaminetetraacetic acid (EDTA), propylene glycol, trolamine, and distilled water, following the recommended mix proportion set by the World Health Organization (WHO).

Despite solving the issue of poor image resolution, the acoustic gel remains a burden in many areas in the world, especially in low-resource communities. The cost of gel diminished the diagnostic value of the procedure. Previous studies reported that the common implementation barriers to utilization of ultrasound in low-resource areas include limited access to consumable supplies required, such as acoustic gel..$^{3-5}$ The use of ultrasound in obstetrics could avert the 295,000 women who died due to complications during childbirth and pregnancy in 2017, ${ }^{6}$ and 2,500,000 neonates who died due to congenital disabilities in $2018 .^{7}$

Scholars examined alternatives to commercial acoustic gel. Olive oil, ${ }^{8}$ cornstarch, ${ }^{9}$ and Saluyot (Corchorus olitorius L.) leaves, ${ }^{10}$ were potential alternatives; however, these had significant drawbacks. These gels have low spreadability and foul smell and require rigorous monitoring of temperature to attain optimum consistency. Also, several chemicals used for the gel preparation induced skin allergies and dermatitis. ${ }^{3,4}$ Pregnant women who comprised the majority of the patients undergoing ultrasound examination may be prone to these skin reactions, which could affect the imaging of the fetus and complicate the pregnancy in general. The production of a safe ultrasound gel, therefore, is of paramount importance.
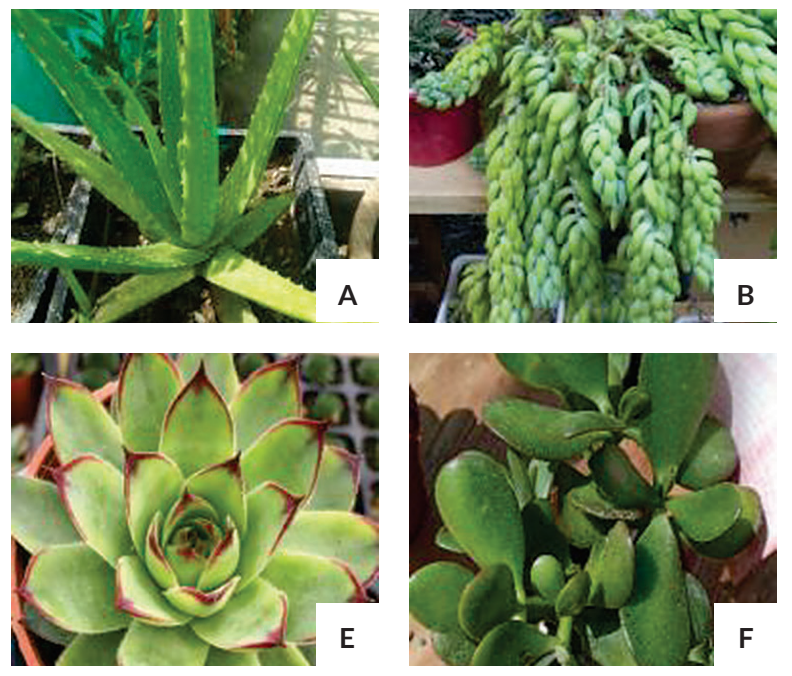

Aloe Vera (Aloe barbadensis miller), common houseleek (Sempervivum tectorum L.), burro's tail (Sedum morganianum L.), snake plant (Sansevieria trifasciata L.), echeveria (Echeveria elegans L.), crown of thorns (Euphorbia milii L.), panda plant (Kalanchose tomentosa L.), and jade plant (Crassula ovata L.) are naturally occurring in tropical countries such as Venezuela, Brazil, India, Thailand, and the Philippines (Figure 1). In the Philippines, these succulents are popular because they are abundant in almost all provinces, such as Metro Manila, Cebu, and Davao. They are widely grown low-maintenance houseplants and are commercially sold as decorations for both outdoors and indoors.

Succulents contain plant parts that are thickened and engorged to retain water to endure arid conditions. Common to all succulent plants is the presence of symplastic water storage, which may be increased by the secretion of polysaccharides to the extracellular spaces, forming a viscous substance known as mucilage, a primary feature of an ideal acoustic gel. ${ }^{11}$ Mucilages are the soluble dietary fibers that are used as thickeners, emulsifying agents, gelling agents, and stabilizers. ${ }^{12}$

Due to the immense call to address the growing concerns of high maternal and neonatal mortality rates in the world, concerted efforts are required to prevent and treat childbirth and pregnancy complications. Ultrasound imaging is of paramount importance in addressing this issue. Hence, the present study addressed the need to find an alternative acoustic gel for ultrasound examinations. It aimed to evaluate the feasibility as measured by the sonographic image quality, organoleptic characteristics, spreadability, $\mathrm{pH}$, and viscosity of various extracts of selected succulents in the Philippines. In doing so, it also attempted to come up with an alternative material that is cheap compared to commercial acoustic gel, readily available, and easy to produce.
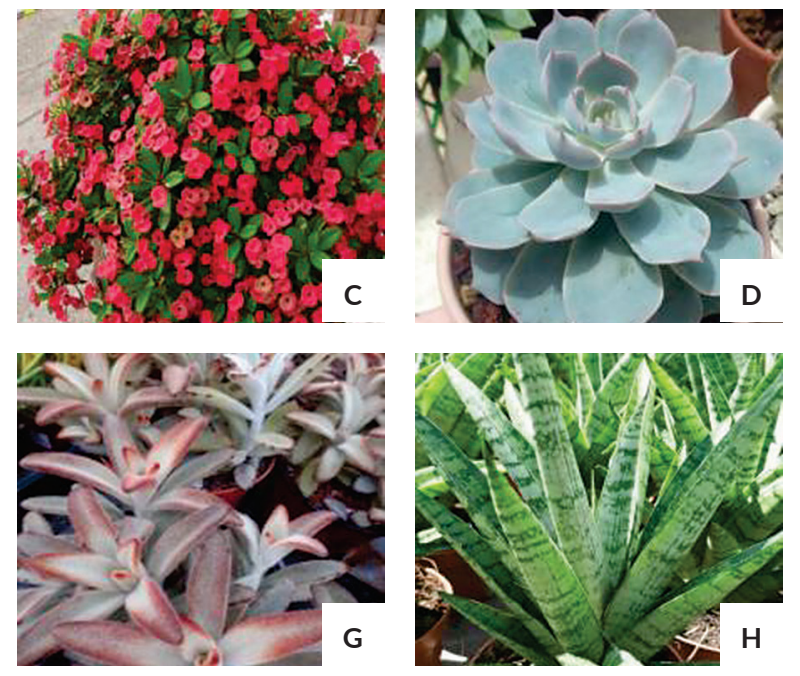

Figure 1. Common Philippine succulents used in the study. (A) Aloe vera (A. barbadensis miller), (B) Burro's tail (S. morganianum L.), (C) Crown of thorns (E. milii L.), (D) Echeveria (E. elegans L.), (E) Common houseleek (S. tectorum L.), (F) Jade plant (C. ovata L.), (G) Panda plant (K. tomentosa L.), (H) Snake plant (S. trifasciata L.). 


\section{MATERIALS AND METHODS}

\section{Collection of Materials}

Aloe Vera, common houseleek, burro's tail, snake plant, echeveria, crown of thorns, panda plant, and jade plant were taken from a local plant nursery in Davao City. This nursery propagates and grows non-genetically modified plants in an organic method. The plants used were specified and verified by a Botanist employed in a higher education institution in Davao City.

\section{Preparation of Acoustic Gels}

The method employed in the development of acoustic gel was adapted and modified from that of Alipio et al. and Riguzzi et al. ${ }^{9,10}$ The plants' leaves were removed from their stems before washing with distilled water. The leaves were weighed, and 1 kilogram of each plant sample was obtained. These were then separately subjected to extraction through an automatic blender machine for 10 minutes. The obtained extract was filtered using a fine mesh strainer to ensure the removal of leaves before placing it into empty acoustic gel containers. The commercial acoustic gel used was AquaSonic 100 Sterile Ultrasound Transmission Gel (Parker Laboratories, Fairfield, New Jersey, USA).

\section{Physical Evaluation of Acoustic Gels}

\section{Organoleptic Characteristics}

The eight formulated acoustic gels and commercial gel were tested for color, homogeneity, immediate skin feel, physical appearance, and texture. Color and physical appearance were based on visual observation, while direct skin feel was assessed by evaluating the greasiness, grittiness, and stiffness of the gels. Homogeneity and texture were determined by pressing the gels between the index finger and thumb and assessing the consistency of and presence of coarse particles in the gels.

\section{Spreadability}

A 1-g sample of each gel was placed between two glass plates $(10 \mathrm{~cm} \times 20 \mathrm{~cm})$ that are horizontally mounted from each other. A 100-g weight board was placed on the upper glass plate to compress the sample. The spreadability of the gels was measured by calculating the spreading diameter after 1 minute. Each gel was tested three times.

\section{$\mathrm{pH}$ values}

A 1-g sample of each gel was dispersed in a $20 \mathrm{~mL}$ deionized water, and a $\mathrm{pH}$ meter was used to calculate for the $\mathrm{pH}$ value of each gel. Measurements were repeated three times.

\section{Viscosity}

A Brookefield Viscometer with a cylinder spindle number 7 was utilized to measure the viscosity of the different acoustic gels. The spindle was rotated at 0-100 rpm values at a temperature of $25^{\circ} \mathrm{C}$, and viscosity was calculated in centiPoise $(\mathrm{cP})$. Viscosity at $50 \mathrm{rpm}$ value was considered. Measurements were done in triplicates.

\section{Analysis of Sonographic Images}

Ultrasound examinations were performed in a human tissue-mimicking phantom using GE Healthcare Ultrasound Machine. The scanning protocols and techniques were adapted from those of Ovel. ${ }^{13}$ The phantom was positioned in supine, and ten $\mathrm{mL}$ of nine acoustic gels (eight succulents' extracts and one commercial acoustic gel) were randomly swabbed into the nine different surfaces of the phantom.

A linear probe was then placed in the phantom's surface, and an ultrasound image was captured and saved. The scan was repeated three times per acoustic gel per surface of the phantom, resulting in 243 saved images (3 repetitions x 9 acoustic gels x 9 surfaces). An 80-kilobyte size of information was allocated per image, and all of the ultrasound machine knobology were set the same for each scan.

Three experienced ultrasonographers, with more than ten years of experience in the clinical practice, separately evaluated the images based on the four image quality parameters, namely the level of acceptability, visibility of detail, amount of recorded detail, and distortion. The evaluators finished both undergraduate and graduate degrees in Radiologic Technology, obtained a board-certified license to practice, and attended a post-graduate ultrasound training program. The evaluators were blinded with the type of acoustic gel used in the image. The same laptop, screen, and room lightning were utilized during the conduct of image evaluation.

\section{Data Collection and Analysis}

Descriptive statistics (mean and standard deviation) were used to describe the average value of the four image quality parameters, spreadability, $\mathrm{pH}$, and viscosity of the tested acoustic gels. One-Way Analysis of Variance (ANOVA) was utilized to compare the quality of images obtained using the tested acoustic gels. A $p$-value of less than 0.05 was considered significant.

\section{RESULTS}

\section{Physical Evaluation of Acoustic Gels}

Table 1 depicts the organoleptic characteristics, including the color, homogeneity, immediate skin feel, physical appearance, and texture of the acoustic gels. The results showed that all acoustic gels obtained from succulents were light green, homogeneous, not greasy, not gritty, not stiff, and smooth. Four acoustic gels were opaque, while the other four had a transparent appearance.

Table 2 shows the spreadability after 1 minute, $\mathrm{pH}$, and viscosity values of the acoustic gels. The results revealed that all of the acoustic gels formulated using succulents had higher spreadability, but lower viscosity compared to 
Table 1. Organoleptic characteristics of the acoustic gels

\begin{tabular}{lccccc}
\hline Type of Acoustic Gel & Color & Homogeneity & Immediate Skin Feel & Physical Appearance & Texture \\
Commercial & White & Homogeneous & Not greasy, not gritty, not stiff & Transparent & Smooth \\
Aloe Vera & Light green & Homogeneous & Not greasy, not gritty, not stiff & Transparent & Smooth \\
Common houseleek & Light green & Homogeneous & Not greasy, not gritty, not stiff & Opaque & Smooth \\
Burro's tail & Light green & Homogeneous & Not greasy, not gritty, not stiff & Transparent & Smooth \\
Snake plant & Light green & Homogeneous & Not greasy, not gritty, not stiff & Opaque & Smooth \\
Echeveria & Light green & Homogeneous & Not greasy, not gritty, not stiff & Transparent & Smooth \\
Crown of thorns & Light green & Homogeneous & Not greasy, not gritty, not stiff & Opaque & Smooth \\
Panda plant & Light green & Homogeneous & Not greasy, not gritty, not stiff & Transparent & Smooth \\
Jade Plant & Light green & Homogeneous & Not greasy, not gritty, not stiff & Opaque & Smooth \\
\hline
\end{tabular}

Table 2. Spreadability, $\mathrm{pH}$, and viscosity values of the acoustic gels $(n=3$, results depicted as mean $\pm \mathrm{SD}$ ) and One-Way ANOVA

\begin{tabular}{lccr}
\hline Type of Acoustic Gel & Spreadability $(\mathrm{mm})$ & \multicolumn{1}{c}{ pH } & \multicolumn{1}{c}{ Viscosity (cPs) } \\
\hline Commercial & $20.17 \pm 0.05$ & $5.62 \pm 0.01$ & $18650.33 \pm 0.47$ \\
Aloe Vera & $27.23 \pm 0.05$ & $4.64 \pm 0.04$ & $8812.33 \pm 1.89$ \\
Common houseleek & $38.07 \pm 0.12$ & $5.46 \pm 0.03$ & $3204.00 \pm 1.41$ \\
Burro's tail & $23.47 \pm 0.05$ & $5.91 \pm 0.06$ & $14539.33 \pm 0.94$ \\
Snake plant & $50.13 \pm 0.05$ & $5.63 \pm 0.03$ & $958.67 \pm 1.70$ \\
Echeveria & $24.67 \pm 0.09$ & $5.98 \pm 0.02$ & $12538.67 \pm 0.47$ \\
Crown of thorns & $49.63 \pm 0.05$ & $5.86 \pm 0.05$ & $1031.33 \pm 0.47$ \\
Panda plant & $28.40 \pm 0.08$ & $5.63 \pm 0.05$ & $7817.00 \pm 2.83$ \\
Jade Plant & $30.13 \pm 0.05$ & $5.51 \pm 0.02$ & $6969.00 \pm 0.82$ \\
F-value & $49645.69^{* * *}$ & $225.69^{* * *}$ & $36038568.69^{* * *}$ \\
\hline
\end{tabular}

${ }^{* * *} p<0.001$

Table 3. Image quality values of the acoustic gels $(n=3$, results depicted as mean \pm SD) and One-Way ANOVA

\begin{tabular}{lcccc}
\multirow{2}{*}{ Type of Acoustic Gel } & \multicolumn{4}{c}{ Image Quality Parameters } \\
\cline { 2 - 5 } & Level of Acceptability & Visibility of Detail & Amount of Recorded Detail & Distortion \\
Commercial & $3.93 \pm 0.39$ & $4.06 \pm 0.51$ & $4.12 \pm 0.51$ & $1.52 \pm 0.25$ \\
Aloe Vera & $3.88 \pm 0.56$ & $4.00 \pm 0.47$ & $3.88 \pm 0.52$ & $1.49 \pm 0.30$ \\
Common houseleek & $4.10 \pm 0.45$ & $4.00 \pm 0.55$ & $4.04 \pm 0.55$ & $1.44 \pm 0.21$ \\
Burro's tail & $3.99 \pm 0.40$ & $4.05 \pm 0.51$ & $4.01 \pm 0.52$ & $1.47 \pm 0.32$ \\
Snake plant & $3.93 \pm 0.43$ & $3.91 \pm 0.44$ & $3.98 \pm 0.47$ & $1.53 \pm 0.21$ \\
Echeveria & $4.24 \pm 0.41$ & $3.90 \pm 0.50$ & $3.94 \pm 0.62$ & $1.51 \pm 0.31$ \\
Crown of thorns & $4.14 \pm 0.41$ & $3.93 \pm 0.37$ & $4.12 \pm 0.50$ & $1.46 \pm 0.30$ \\
Panda plant & $3.99 \pm 0.46$ & $3.91 \pm 0.55$ & $3.78 \pm 0.47$ & $1.41 \pm 0.31$ \\
Jade Plant & $4.12 \pm 0.55$ & $3.93 \pm 0.54$ & $3.99 \pm 0.47$ & $1.48 \pm 0.27$ \\
F-value & $1.90^{\text {ns }}$ & $0.43^{\text {ns }}$ & $1.25^{\mathrm{ns}}$ & $0.54^{\mathrm{ns}}$ \\
\hline
\end{tabular}

${ }^{n s}$ not significant $(p>0.05)$

commercial acoustic gel. Among the formulated acoustic gels, burro's tail had the highest viscosity but had the lowest spreadability. The snake plant had the most moderate viscosity but had the highest spreadability based on the analysis. The $\mathrm{pH}$ of all of the acoustic gels was slightly acidic. The spreadability, $\mathrm{pH}$, and viscosity values were statistically different among the acoustic gels used $(p<0.05)$.

\section{Analysis of Sonographic Images}

The analysis of sonographic images indicated that all of the formulated acoustic gels had a comparable level of acceptability, visibility of detail, amount of recorded detail, and distortion to that of commercial products (Table 3). The results also reported that the image quality parameters were statistically the same for all the acoustic gels tested $(p>0.05)$.

\section{DISCUSSION}

Eight different acoustic gels were formulated from the common succulents in the Philippines. The formulation utilized a simple extraction method, and the obtained extracts were physically evaluated based on their organoleptic characteristics, spreadability, $\mathrm{pH}$, and viscosity. Three evaluators analyzed the sonographic images obtained after a series of ultrasound scans based on four image quality parameters, namely, the level of acceptability, visibility of detail, amount of recorded detail, and distortion.

The physical analysis revealed that the eight formulated acoustic gels had optimal appearance, texture, and homogeneity. All of the formulations had a light green color. In the study, the tested succulents are plants containing 
water-storing tissues in one or more parts. ${ }^{14,15}$ The primary sites of water storage for these plants are called simple parenchyma cells. ${ }^{15}$ These cells contain chlorophyll, giving the plants' extracts their light green color. ${ }^{16}$

The tests for spreadability and viscosity revealed that the acoustic gels from the succulents exhibit a higher spreadability, but a lower viscosity compared to the commercial gel. Burro's tail had the highest viscosity but had the lowest spreadability. The snake plant had the lowest viscosity but had the highest spreadability based on the analysis. The spreadability of a given formulation is the ability to spread evenly on the skin surface. Previous studies reported that this parameter plays a significant role in the application of gel for medical purposes ${ }^{17,18}$; however, in ultrasound examinations, the acoustic gel is not used as a therapeutic agent but functions primarily to enhance the transmission of sound waves from the probe to the organ of interest.

On the other hand, the viscosity of a given formulation refers to its thickness due to internal friction. This parameter is one of the more important factors to be considered in the development of acoustic gel. ${ }^{2}$ Highly viscous fluids contain molecules arranged much close together compared to fluids with low viscosity. ${ }^{19}$ Sound waves travel faster in molecules that are packed together compared to loosely packed molecules. ${ }^{20}$ As observed in the study, the extracts of burro's tail had the highest viscosity, among others. Previous studies showed that the mucilage substance found in water-storing tissues of succulents accounted for the viscosity of the plants' extract. ${ }^{11,14,15}$

In terms of $\mathrm{pH}$, the $\mathrm{pH}$ of all of the acoustic gels was slightly acidic. The $\mathrm{pH}$ of a given formulation for application should match the $\mathrm{pH}$ of the skin to avoid skin allergies and other reactions. The $\mathrm{pH}$ of the skin ranges from 4 to $7 .{ }^{21}$ The tested acoustic gels were optimal in terms of $\mathrm{pH}$ as results matched to skin's normal $\mathrm{pH}$ range. Previous gel alternatives failed to address skin sensitivity issues of the produced gel. ${ }^{3,8,10}$ This study offers significant novelty as it firstly reports the $\mathrm{pH}$ of all tested alternatives and considers this factor in the formulation to avoid skin allergies that could happen during any ultrasound examination.

The analysis of image quality parameters demonstrated that all of the formulated acoustic gels were comparable to the commercial gel in terms of the level of acceptability, visibility of detail, amount of recorded detail, and distortion. The level of acceptability refers to the adequacy of the image for diagnostic interpretation, while the visibility of detail refers to the clarity of the structures of a given organ. The amount of recorded detail refers to the sharpness of the structures of pertinent anatomy, and distortion refers to the misrepresentation of the anatomy scanned in the image display. The levels of acceptability, visibility of detail, amount of recorded detail, and distortion were robust indicators of image quality in ultrasound practice. ${ }^{13}$ Similar to a previous report, the image quality parameters were statistically identical among the formulated and commercial acoustic gels. ${ }^{9}$ However, a previous study using Saluyot (Corchorus olitorius L.) gel demonstrated statistically higher visibility of detail and amount of recorded detail compared to the commercial acoustic gel. ${ }^{10}$ The differences in the results of previous research could be attributed to the number of ultrasonographers who rated the image quality of the sonographic images. Both studies employed only one ultrasonographer and did not mention the clinical experience or the prior training received by the evaluator. Employing only one ultrasonographer with no clinical expertise as an evaluator of images could provide flawed results and interpretation of image quality as the evaluator had no prior knowledge in sonographic images. To control for the possible variation in the ratings, the present study recruited three ultrasonographers with more than ten years of experience in the clinical practice. In comparison to the previous studies, all of the ultrasonographers were blinded by the type of ultrasound gel used during evaluation to avoid potential rating biases. Also, the assessment took place in a separate room using the same laptop, screen, and room lightning to control possible external factors that could affect the rating. Using a highly controlled sonographic image evaluation, the SDs of image quality parameters were less than 0.60 , which represents homogeneity of responses from the ultrasonographers. Future studies may consider including interrater analyses to control for the rater-dependence nature of sonographic image evaluation.

The extracts of the common Philippine succulents could be a superior alternative to commercial acoustic gel for ultrasound examinations, especially in low-resource communities. The Philippines and other developing countries that are currently experiencing issues regarding ultrasound use and availability of ultrasound gel could benefit from the several advantages of the tested extracts. The succulents are cheaper, readily available, and easy to produce compared to the commercial acoustic gel and previous gel alternatives. Cornstarch, cassava, and olive oil-based gels, although cheap, have economic value in tropical countries and are widely used as food product agents. ${ }^{3,8}$ The production of these gels requires rigorous temperature checks to attain optimal consistency. In the study, the succulents were only subjected to simple extraction and filtration methods and yield a comparable image quality to that of commercial acoustic gel. One observed advantage of the alternative gel was its low volatility compared to the widely used alcohol-based commercial gel. Compared to the succulents, alcohol-based commercial gel readily evaporates, thereby requiring more volume to complete a single ultrasound examination.

\section{CONCLUSION}

The study showed that all of the tested extracts of common Philippine succulents had optimal appearance, texture, homogeneity, and $\mathrm{pH}$ value. However, all of the extracts had a lower viscosity than the commercial reference 
gel. The extract obtained from burro's tail exhibited the highest viscosity among the tested extracts. Future studies may be conducted to optimize the extract's viscosity comparable to that of the commercial gel. Although a difference in viscosity exists among the tested extracts and commercial gel, the study reported no significant difference in the image quality parameters among the gels used. Moreover, based on the physical evaluation, $\mathrm{pH}$, spreadability, and image quality, the extracts obtained from the succulents are feasible as an acoustic gel for ultrasound imaging.

\section{Recommendation}

In light of the findings and conclusions, several recommendations are formulated. Future investigation may be conducted to optimize the viscosity of the selected succulents, especially burro's tail. The test of stability on the organoleptic characteristics, viscosity, $\mathrm{pH}$, spreadability, and image quality parameters may be undergone for some time to observe for changes in the properties of the extracts. Actual patients in the low-resource settings may be scanned in future studies using the extracts. This study does not answer questions relating to the ease of use of the gel and subjective assessment of gel consistency while being used in clinical practice; however, it is observed during the study that the tested succulents do not evaporate through time and remain in the phantom even after the completion of ultrasound examination.

Nevertheless, the mentioned parameters are essential considerations for further research. In addition to ultrasonographers, ultrasound radiologists should be included as evaluators of image quality in future research to further provide accurate analysis of the images. Although other succulents may be tested, the present study is the first to explore and prove the feasibility of the extracts of common Philippine succulents (Aloe Vera, common houseleek, burro's tail, snake plant, echeveria, crown of thorns, panda plant, and jade plant) as ultrasound acoustic gel. Moreover, the study recommended alternative materials that are readily available and easy to produce compared to commercial acoustic gel.

\section{Statement of Authorship}

All authors participated in data collection and analysis, and approved the final version submitted.

\section{Author Disclosure}

All authors declared no conflicts of interest.

\section{Funding Source}

This study received no external funding.

\section{REFERENCES}

1. Odwin CS, Fleischer AC. Lange review ultrasonography examination with CD-ROM. McGraw Hill Professional; 2012.

2. Rumack C. Diagnostic ultrasound. St. Louis: Elsevier Mosby. 2011.

3. Salmon M, Salmon C, Bissinger A, Muller MM, Gebreyesus A, Geremew $\mathrm{H}$, et al. Alternative ultrasound gel for a sustainable ultrasound program: application of human centered design. PLoS One. 2015;10(8): e0134332. doi.org/10.1371/journal.pone.0134332.

4. Shah S, Bellows BA, Adedipe AA, Totten JE, Backlund BH, Sajed D. Perceived barriers in the use of ultrasound in developing countries. Crit Ultrasound J. 2015;7(1):28. doi: 10.1186/s13089-015-0028-2. Epub 2015 Jun 19.

5. Shah S, Noble VE, Umulisa I, Dushimiyimana J, Bukhman G, Mukherjee J, et al. Development of an ultrasound training curriculum in a limited resource international setting: successes and challenges of ultrasound training in rural Rwanda. Int J Emerg Med. 2008 Sep;1(3):193-6. doi: 10.1007/s12245-008-0053-z. Epub 2008 Sep 25.

6. Hug L, Sharrow D, You D. Levels \& trends in child mortality: report 2019. Estimates developed by the UN Inter-agency Group for Child Mortality Estimation. [Internet] 2019 [cited 2018 December 3) Available from: https://www.unicef.org/media/60561/file/UNIGME-child-mortality-report-2019.pdf.

7. WHO. Trends in maternal mortality: 2000 to 2017. estimates developed by WHO, UNICEF, UNFPA and The World Bank. [Internet] 2019 [cited 2018 December 3) Available from: http:// documents.worldbank.org/curated/en/793971568908763231/ pdf/ Trends-in-maternal-mortality-2000-to-2017-Estimates-by-WHOUNICEF-UNFPA-World-Bank-Group-and-the-United-NationsPopulation-Division.pdf.

8. Luewan S, Srisupundit K, Tongsong T. A comparison of sonographic image quality between the examinations using gel and olive oil, as sound media. J Med Assoc Thai. 2007;90(4):624-627.

9. Riguzzi C, Binkowski A, Price D, Fahimi J. Evaluation of a cornstarchbased ultrasound gel alternative for low-resource settings. J Emerg Med. 2014 Jul;47(1):e5-9. doi:10.1016/j.jemermed.2013.08.073. Epub 2013 Nov 12.

10. Alipio MM, Questo DLR, Subang DMI, Tan LA. Saluyot (Corchorus olitorius L.) leaves as acoustic gel for ultrasound imaging. CMU Journal of Science. Forthcoming 2020.

11. Griffiths H, Males J. Succulent plants. Curr Biol. 2017;27(17): R890-R6. doi: 10.1016/j.cub.2017.03.021.

12. Fuller S, Beck E, Salman H, Tapsell L. New horizons for the study of dietary fiber and health: a review. Plant Foods Hum Nutr. 2016 Mar;71(1):1-12. doi: 10.1007/s11130-016-0529-6.

13. Ovel S. Sonography exam review: physics, abdomen, obstetrics and gynecology-e-book. Elsevier Health Sciences; 2014.

14. Eggli U. Illustrated handbook of succulent plants: Crassulaceae. Springer Science \& Business Media; 2012.

15. Grace OM. Succulent plant diversity as natural capital. Plants, People, Planet. 2019;1:336-45.

16. Vernon LP, Seely GR. The chlorophylls. Academic Press; 2014.

17. Rajan R, Vasudevan DT. Effect of permeation enhancers on the penetration mechanism of transfersomal gel of ketoconazole. J Adv Pharm Technol Res. 2012 Apr-Jun; 3(2): 112-6. doi: 10.4103/22314040.97286.

18. Uprit S, Sahu RK, Roy A, Pare A. Preparation and characterization of minoxidil loaded nanostructured lipid carrier gel for effective treatment of alopecia. Saudi Pharm J. 2013 Oct;21(4):379-85. doi: 10.1016/j.jsps.2012.11.005.

19. Hargraves RB. Physics of magmatic processes. Princeton University Press; 2014.

20. Kruth P, Stobart H. Sound. Cambridge University Press; 2007.

21. Lambers H, Piessens S, Bloem A, Pronk H, Finkel P. Natural skin surface $\mathrm{pH}$ is on average below 5, which is beneficial for its resident flora. Int J Cosmet Sci. 2006 Oct;28(5):359-70. doi: 10.1111/j.14672494.2006.00344.x. 